\title{
A JUDICIALIZAÇÃO DA INCLUSÃO: O GOVERNO PELA LEI
}

\author{
THE JUDICIALIZATION OF THE INCLUSION PROCESS: \\ GOVERNING THROUGH LAW
}

\author{
Adriana da Silva Thoma ${ }^{\dagger}$ \\ Betina Hillesheim $^{1}$ (D) \\ Carolina de Freitas Corrêa Siqueira ${ }^{2, *}$ (D)
}

\begin{abstract}
RESUMO: O artigo discute a judicialização da inclusão, compreendendo-a como ações desenvolvidas pelo Poder Judiciário voltadas à inclusão de grupos em situação de risco ou vulnerabilidade social. Para as análises, utiliza-se a noção de governamentalidade biopolítica, na perspectiva de Michel Foucault. Argumenta-se que, por meio do Poder Judiciário, o Estado regula os rumos da inclusão a partir de dois vieses que se articulam: o da fiscalização e da intervenção recomendatória e o da orientação, que toma a argumentação e o convencimento como formas de produzir modos de ser inclusivos.
\end{abstract}

Palavras-chave: Inclusão. Judicialização. Governamentalidade biopolítica.

ABSTRACT: This paper discusses the judicialization of inclusion, by understanding it as actions taken by the Judicial Power intended for the inclusion of groups in situation of social risk and vulnerability. To perform the analyses, Michel Foucault's notion of biopolitical governmentality was utilized. It was argued that, through the Judicial Power, the State regulates the course of inclusion through two articulated paths: one consisting of oversight and recommended intervention, and the other implying guidance, by regarding argumentation and persuasion as ways of producing inclusive ways of being.

Keywords: Inclusion. Judicialization. Bio-political governmentality.

1.Universidade de Santa Cruz do Sul - Santa Cruz do Sul (RS), Brasil.

2.Universidade Federal do Rio Grande do Sul - Porto Alegre (RS), Brasil.

†.In Memoriam

*Autora correspondente: carolinafcsiqueira@gmail.com

Número temático organizado por: Adriana da Silva Thoma (I.M.) e Betina Hillesheim 


\section{Introdução}

"O código penal é a regra do jogo em qualquer país"

(La Casa de Papel, episódio 13, temporada 1)

- Porto Alegre, 17 de abril de 2017. O Ministério Público do estado do Rio Grande do Sul, por meio da Promotoria de Justiça Regional de Educação de Porto Alegre (RS), emite a RECOMENDAÇÃO n. 03/2017 para instituições de ensino privadas do município. Tal recomendação foi emitida após a Promotoria constatar que o Atendimento Educacional Especializado (AEE) não estava sendo ofertado de acordo com as determinações legais. Diante disso, a Promotoria procurou universidades para discutir a oferta de cursos de formação continuada, uma vez que a justificativa principal das escolas para o não atendimento da oferta do AEE era a insuficiente formação dos professores. Na sequência, a Promotoria promoveu reuniões com gestores e professores das escolas para acompanhamento do processo, assumindo o compromisso de buscar alternativas junto às equipes diretivas. Além disso, a Promotoria emitiu tal recomendação, na qual estabelece que "as providências adotadas deverão ser informadas paulatinamente ao Ministério Público, conforme os prazos indicados, através do protocolo dos documentos comprobatórios", e que "a inobservância da recomendação poderá ensejar o ajuizamento de AÇÃO CIVIL PÚBLICA, com pedido de liminar, para regularização das questões pendentes" (RIO GRANDE DO SUL, 2017, p. 20).

- Rio de Janeiro, 11 de maio de 2018. O Ministério Público do Trabalho (MPT), por meio dos membros do Grupo de Trabalho instituído pela Coordenadoria Nacional de Promoçãoà Igualdade e Combate à Discriminação no Trabalho (COORDIGUALDADE), resolve "RECOMENDAR à empresa GLOBO COMUNICAÇÕES E PARTICIPAÇÕES S. A. a observância de deveres de conduta, os quais constituem pressupostos de constituição democrática e regular da relação de trabalho artístico, jornalístico, técnico e de produção, sob pena de, em não o fazendo, o labor se tornar excludente e discriminatório, sujeitando a Organização Globo às medidas judiciais cabíveis" (RIO DE JANEIRO, 2018, p. 8). A recomendação é decorrente da repercussão da estreia, em 2018, da novela Segundo Sol, e está pautada em um conjunto de documentos legais que tratam sobre a promoção da igualdade racial e combate ao racismo no Brasil. A questão se refere ao baixo número de atores negros no elenco, tendo em vista que a produção artística da novela é ambientada na Bahia, que, segundo o IBGE (2013), possui o maior percentual da população negra do país. O MPT argumenta que a falta de representatividade negra em programas televisivos reforça estereótipos e variadas formas de exclusão dos negros. Assim, designa ações específicas para contemplar medidas de inclusão, superação do racismo e afirmação da identidade negra. Ao final, consta que "a empresa deverá comprovar nos autos as providências adotadas para o cumprimento da presente notificação, no prazo de 10 (dez) dias a partir do recebimento, no que tange às medidas adotadas em relação à participação de atores e atrizes negros e negras na novela Segundo Sol, e de 45 (quarenta e cinco) dias, no que concerne aos demais tópicos, com a apresentação de cronograma de trabalho, inclusive informando as grades de horários para veiculação das campanhas institucionais pertinentes" (IBGE, 2013, p. 11). A recomendação explicita que "a empresa será submetida ao competente acompanhamento, 
a contar da presente data, com a finalidade de verificação da adequação de sua conduta ao disposto na presente Notificação Recomendatória. O descumprimento da recomendação poderá caracterizar inobservância de norma de ordem pública” (IBGE, 2013, p. 11). A notificação foi expedida com prazo indeterminado, "podendo o Ministério Público, a qualquer momento, solicitar/requisitar informações sobre o respectivo cumprimento" (IBGE, 2013, p. 11).

No processo de efetivação de direitos, particularmente no período pós-democratização do país, os processos de in/exclusão acontecem por meio de políticas voltadas à promoção da cidadania. A inclusão, no final da década de 1980 e início dos anos 1990, emerge no Brasil na lógica de uma “'governamentalidade democrática’, na qual o centro é o cidadão. É nesse contexto que o valor fundamental a ser afirmado seja o da cidadania" (GALLO, 2015, p. 332). Em um cenário marcado pela lógica da democracia, o discurso da inclusão é produzido como uma verdade que busca atingir a todos. Todavia, em algumas situações, há a necessidade de recorrer ao âmbito judiciário para que se definam os encaminhamentos, criando-se estratégias para a produção de sujeitos inclusivos (MENEZES, 2011). Considerando que, como colocado na epígrafe deste texto, o Código Penal seja a regra do jogo em qualquer país, trazemos as recomendações como disparadores para a discussão sobre o que estamos denominando judicialização da inclusão.

A judicialização da inclusão envolve processos mobilizados para o cumprimento das determinações legais que visam promover a inclusão. Neste artigo, escolhemos duas situações que se referem a categorias específicas de sujeitos - população de pessoas com deficiência e população negra. Tais grupos sofrem o que Castel (2007) nomeia como discriminação negativa, constituindo alvos de uma crescente regulação do Estado no sentido da inclusão.

Com Meyer e Paraíso (2012,p. 21), entendemos que "precisamos ser pesquisadores(as) conectados(as) com os desafios educacionais, culturais, sociais e políticos do nosso tempo" e que o tempo em que vivemos "demanda de nós não apenas a compreensão do mundo em que vivemos, mas, sobretudo, a criação de instantes de suspensão dos sentidos já criados e a abertura de possibilidades de sua ressignificação”. Neste texto, escrito a seis mãos, apresentamos algumas questões que temos discutido coletivamente nos grupos de pesquisas dos quais participamos. Neles, produzimos conhecimentos por meio da problematização das estratégias utilizadas para a inclusão, a subjetivação e o governamento de sujeitos que compõem os chamados grupos em situação de exclusão, risco ou vulnerabilidade social. Nesse sentido, a judicialização apresentou-se para nós como um tema a ser analisado e discutido, dada a sua recorrência na fala de professores e gestores com quem temos produzido dados para a pesquisa em encontros de formação, em reuniões no Ministério Público para tratar do Atendimento Educacional Especializado, bem como em outros acontecimentos que envolvem os grupos e sujeitos com e sobre os quais desenvolvemos nossas investigações.

Para o desenvolvimento das análises, utilizamos a noção de governamentalidade biopolítica. No curso Segurança, Território e População, Foucault (2008) discute a problemática do biopoder, deslocando-se para o que chamou de governamentalidade. A governamentalidade é um tipo de poder que se volta para a população: seu objetivo é a sociedade; seu objeto, a conduta dos sujeitos; suas estratégias, a política e a economia.

Segundo Nogueira (2009), a governamentalidade apresenta-se como uma noção teórica, uma ferramenta para pensar. Assim, tomamos a governamentalidade como uma ferramenta para operar análises sobre a judicialização, entendendo essa última como uma estratégia de condução de condutas - uma estratégia de governamento - para que a inclusão aconteça. Na medida em que, no cenário da in/exclusão, são produzidos modos de gestão de vidas, a realização de uma análise a partir desse prisma significa empreender esforços na produção de esquemas de compreensão capazes de questionar aquilo que parece incontestável, 
como é o caso da própria inclusão. O termo governamento, para Veiga-Neto (2005), seria o mais adequado para referir a todas as ações utilizadas por um Governo sobre aquele que deseja governar. O autor propõe a palavra governamento para diferenciar Governo (com "G" maiúsculo - aquele que governa) de gouvernement (ações de condução das condutas de uma população).

Nas recomendações analisadas, o Ministério Público age promovendo encontros com professores e gestores referentes à implementação e à oferta do atendimento educacional especializado, ou exigindo maior representatividade negra. Argumentamos que, embora a inclusão esteja inscrita em um contexto de garantia de direitos, produção de condutas inclusivas e estabelecimento de outros modos de relação com as diferenças requerem a intervenção do Estado. Sendo assim, compreendemos que a necessidade de intervenção acontece quando não houve o convencimento de que direitos são inegociáveis dentro da lógica de uma governamentalidade democrática e da constituição de subjetividades inclusivas.

Assim, desenvolvemos uma discussão sobre a judicialização da inclusão, buscando pensá-la não no sentido de um obrigar a fazer, mas de como ela se inscreve em uma lógica de práticas de liberdade, em uma sociedade que se pretende inclusiva. A seguir, contextualizamos as recomendações nas normativas legais brasileiras, problematizando-as como estratégias de constituição de subjetividades inclusivas. Para finalizar, argumentamos que, embora a inclusão possa ser analisada como um imperativo de Estado inscrito em um espaço gerido por uma governamentalidade biopolítica, o objetivo de produzir novas relações com as diferenças coexiste com processos de invisibilização/exclusão de grupos sociais, étnicos e culturais. Compreendemos que, apesar da busca pela captura da maior margem populacional possível, o que caracteriza ações promovidas no âmbito da governamentalidade biopolítica, pode ser percebido como cenário de ambiguidades no que tange às formas como a inclusão das diferenças se inscreve (ou não) em determinados lugares.

\section{A Judicialização da Inclusão}

Para desenvolvermos a discussão, partimos de alguns pressupostos. O primeiro é que a inclusão constitui um direito cujas condições de emergência ocorrem a partir do período de redemocratização do Brasil, quando os movimentos sociais ganham força nas lutas de afirmação de direitos. Nesse contexto, são promulgadas legislações que buscam garantir a efetivação de direitos, particularmente os que se referem a sujeitos historicamente excluídos. Contudo, "somente em uma ficção pode se fazer crer que as leis são feitas para serem acatadas", pois "todo o dispositivo legislativo organizou espaços protegidos e aproveitáveis, em que a lei pode ser violada, outros, em que pode ser ignorada, outros, enfim, em que as infrações são sancionadas" (FOUCAULT, 1975 apud POL-DROIT, 2006, p. 50).

O segundo pressuposto é que a inclusão, como manifestação da arte de governar a partir da liberdade (HILLESHEIM; BERNARDES, 2015), é uma invenção de nosso tempo e uma estratégia biopolítica. $\mathrm{Na}$ construção de documentos legais, há, por um lado, um chamamento à participação da sociedade, gerando a ideia de que o envolvimento de todos é importante para a construção das diretrizes, leis e políticas; por outro, a construção coletiva visa assegurar aquilo que Foucault (2013) denomina tranquilidade pública, a cargo do Estado. Com isso, o ajuste da maneira de governar e um governo de si se darão "na forma do universal (como discussão pública, raciocínio público e uso público do entendimento)", acarretando a obediência de "todos os que fazem parte de uma sociedade dada, de um Estado dado, de uma administração dada” (FOUCAULT, 2013, p. 37).

O terceiro pressuposto é que, a partir de uma governamentalidade neoliberal, a inclusão entra nas lógicas econômica e social, produzindo modos de vida que se inscrevem nessa racionalidade. O Estado, para colocar a inclusão em funcionamento, desenvolve estratégias de governamento para produzir sujeitos 
inclusivos e incluídos. Entretanto, tais estratégias não capturam a todos e, diante do não cumprimento do que a legislação determina, a judicialização apresenta-se como possibilidade de garantia de direitos.

Nesse cenário, a judicialização tem sido um fenômeno crescente, acontecendo em áreas como a saúde, a assistência social e a educação. Diante disso, ao buscarmos estudos que analisem essa questão, evidenciamos uma primeira distinção entre os posicionamentos referentes aos processos de judicialização: por um lado, há aqueles que entendem que a judicialização é necessária no sentido de garantia de direitos, colocando-a na esfera da proteção social; por outro, há posições que problematizam a ideia de proteção, entendendo-a como regulação de formas de viver. Dessa maneira, a própria questão da judicialização é complexa e ambivalente, pois, mesmo a favor da inclusão, essa pode ser compreendida dentro de uma lógica punitiva e de controle.

Tibério afirma que, nos processos de judicialização das relações escolares:

"se verifica a ampla circulação de termos como 'segurança', 'gestão de riscos', 'necessidade de proteção', 'dano', 'vulnerabilidade, 'judicialização', entre outros, o que aponta para intensos movimentos em relação a políticas de controle e vigilância" (Tibério, 2011, p.6).

Por sua vez, Chrispino e Chrispino (2008) destacam a responsabilidade civil dos educadores, apresentando decisões da justiça brasileira de ações envolvendo as escolas e salientando a necessidade de firmar-se um novo pacto entre os atores educacionais, a fim de preparar os educadores para que possam dar direção e tomar decisões sobre o universo escolar.

Para Oliveira e Brito, a judicialização consiste no "movimento de regulação normativa e legal do viver, do qual os sujeitos se apropriam para a resolução dos conflitos, reproduzindo uns com os outros o controle, o julgamento e a punição das condutas" (2013, p. 79). Os autores ressaltam que, muitas vezes, a partir de uma justificativa de proteção, tais ações se pautam em uma lógica segregativa e individualizante, mediante "políticas penais repressivas, violentas e estigmatizantes" (OLIVEIRA; BRITO, 2013, p. 85). Nessa perspectiva, Reis, Guareschi e Carvalho (2014) argumentam que o processo judicial constitui uma forma de autenticar, adquirir ou transmitir verdades, aliando-se a diferentes discursos (como, por exemplo, a ideia de proteção para a Psicologia ou para o Direito) para obter legitimidade.

No caso das recomendações trazidas neste artigo, essas se voltam para instituições (escolas da rede privada e Grupo Globo de Comunicações), a fim de obrigá-las a fazer o que está previsto na legislação. Entretanto, à semelhança de outras situações, há um movimento de regulação de condutas, respaldado pelos Direitos Humanos e pela noção de proteção, constituindo sujeitos e instituições adequados ao que se entende como desejável para nossa época.

Segundo Lemos (2013), as práticas punitivas não se dão apenas pelo Estado e pelo Direito Penal, visto que os mecanismos disciplinares ocorrem nas adjacências do Poder Judiciário. Citando obra de Castel de 1987 (apud LEMOS, 2013), a autora alerta que, desde o final do século XX, há uma gestão de riscos que opera na lateralidade do Poder Judiciário e que age por meio de especialistas da norma que atuam na direção da inclusão social. Contudo, para além de riscos, o que existiria seriam cálculos virtuais que os engendram, sendo que, na constituição de um dispositivo jurídico-administrativo, caberia a aplicação de punições e encaminhamentos para serviços equipados para a administração social dos riscos. Tal gestão insere-se na ideia de proteção como controle, caracterizando-se por uma capilaridade de ações, tanto no sentido de compensação de determinados sujeitos e grupos quanto no de administração de desempenhos.

Assim, das recomendações derivam ações para fazer a inclusão acontecer, por meio da vontade produzida pelos argumentos legais que as sustentam. Afinal, como coloca Foucault, “o motor de ação é o 
desejo" (2008, p. 95). Isso significa que, mediante tais ações, os pensamentos e as relações de uns com os outros e de cada um consigo mesmo poderão ser coordenados e dirigidos; ou seja, governados, fazendo agir. As recomendações são, pois, instruções que têm por objetivo regular as condutas de todos para que se tornem inclusivas. A lei, nesse caso, não deve ser vista somente como imposição, o que causaria mais resistências; a lei precisa ser compreendida a partir da noção de direitos e de cidadania; e a inclusão, como meta.

Trata-se de um enlace sutil entre obrigar e deixar fazer: a lei atua também como parte de produção de verdades, constituindo subjetividades inclusivas. É interessante apontar, portanto, que, nos casos analisados, são recomendações. Recomendação, em seu sentido dicionarizado, remete a:

- Ato ou efeito de recomendar;

- Indicação positiva a respeito de alguém ou de algo;

- Aviso ou advertência a respeito de algo; conselho;

- Qualidade do que é recomendável ${ }^{1}$.

Recomendar, portanto, está mais relacionado com a condução de condutas do que com um ato de dominação. Assim, para produzir condutas desejáveis, recomenda-se... Afinal, "quanto mais liberdade para o pensamento vocês deixarem, mais vocês terão certeza de que o espírito do povo será formado para a obediência" (FOUCAULT, 2013, p. 37).

\section{"Atendimento Educacional Especializado" e "Representatividade Negra": a Constituição de Subjetividades Inclusivas}

Tendo em vista o panorama traçado, problematizamos as recomendações como exemplos da "produção do interesse coletivo pelo jogo do desejo" (FOUCAULT, 2008, p. 95). Assinalamos que, se são criadas leis e políticas de inclusão no Brasil, é porque a exclusão ainda existe, mesmo diante de um amparo legal que data do fim dos anos 1980. Assim, além do amparo da lei, são necessárias ações que produzam a inclusão como uma verdade.

A Recomendação n. 03/201, emitida para instituições de ensino privadas do município de Porto Alegre pelo Ministério Público do Rio Grande do Sul, está respaldada em documentos legais nacionais e internacionais. Da Constituição Federal (BRASIL, 1988), é destacado que "a educação é um direito de todos e dever do Estado e da família" e que "a criança e o adolescente têm direito à prioridade absoluta na implementação dos direitos inerentes à dignidade da pessoa humana, como a educação", apontando a igualdade de condições para o acesso e a permanência na escola.

A Constituição Federal assegura, ainda, que a educação será efetivada mediante a garantia de "atendimento educacional especializado aos portadores de deficiência, preferencialmente na rede regular de ensino" (Art. 208, inciso III). Assim, a Lei de Diretrizes e Bases da Educação entende por educação especial "a modalidade de educação escolar, oferecida preferencialmente na rede regular de ensino" e estabelece que "haverá, quando necessário, serviços de apoio especializado, na escola regular, para atender às peculiaridades da clientela de educação especial” (BRASIL, 1996).

Em 1994, é assinada, na Espanha, a Declaração de Salamanca, um pacto internacional sobre a inclusão. Nesse escopo, no Brasil, a partir da segunda metade dos anos 1990, vários materiais informativos foram produzidos pelo Ministério da Educação, visando promover a inclusão escolar. Dessa forma, mediante financiamentos obtidos junto à ONU, foram produzidos e distribuídos materiais que tratavam sobre as pessoas 
com deficiência e seus direitos. Tais materiais objetivavam sensibilizar e mobilizar para a inclusão, o que possibilitou uma expansão dos movimentos sociais das pessoas com deficiência, que passaram a ter maiores visibilidade e alcance nas ações de reinvindicação de direitos (THOMA; KRAEMER, 2017).

A determinação de que a inclusão das pessoas com deficiência ocorra na escola regular também é feita pela Convenção Internacional sobre os Direitos das Pessoas com Deficiência, promulgada no país pelo Decreto n. 6.949/2009 (BRASIL, 2009a). A Convenção visava "garantir o monitoramento e o cumprimento das obrigações do Estado quanto às conquistas históricas da sociedade mundial, principalmente em relação aos 24,9\% de brasileiras e brasileiros com algum tipo de deficiência, conforme levantamento estatístico realizado em 2012" (THOMA; KRAEMER, 2017, p. 68). Composta por artigos que abordam os direitos dessa população, a convenção entende que "se não houver acessibilidade, significa que há discriminação, condenável do ponto de vista moral e ético e punível na forma da lei” (BRASIL, 2009a, p. 1).

Do Decreto n. 5.296/2004 (BRASIL, 2004), que fixa normas de acessibilidade a ser observadas pelas escolas, são feitos destaques pela recomendação, particularmente quanto ao apoio especializado oferecido por meio de serviços e recursos de acessibilidade em salas específicas. Também são feitas referências ao Decreto n. 7.611/2011, que normatiza o atendimento educacional especializado nas escolas do Brasil e determina que "a educação especial deve garantir os serviços de apoio especializado voltado a eliminar as barreiras que possam obstruir o processo de escolarização de estudantes com deficiência, transtornos globais do desenvolvimento e altas habilidades ou superdotação" e que "o atendimento educacional especializado deve integrar a proposta pedagógica da escola" (BRASIL, 2011). A Resolução CNE/CEB n. 04/2009 (BRASIL, 2009b), do Conselho Nacional de Educação, também é mencionada na recomendação, alertando que o projeto pedagógico da escola deve institucionalizar a oferta do AEE, mediante a previsão de dispositivos e recursos que maximizem esse atendimento.

São referidas ainda as Normas fixadas pelo Conselho Estadual de Educação do RS, o Parecer CEED-RS n. 211/2010 (RIO GRANDE DO SUL, 2010), relativo à avaliação e certificação dos alunos com deficiência, o Parecer n. 1.400/2002 do Conselho Estadual de Educação do RS (RIO GRANDE DO SUL, 2002), que fixa normas sobre o Ensino Fundamental e a garantia do padrão de qualidade, recomendando o número máximo de alunos por turma, e o Parecer n. 56/2006 (RIO GRANDE DO SUL, 2006) que estabelece normas para a inclusão de alunos com deficiência e recomenda número máximo desses alunos na formação das turmas. As Notas Técnicas do MEC - CGPEE/GAB n. 15/2010 (BRASIL, 2010b) e SEESP/GAB n. 19/2010 (BRASIL, 2010c), que regulam a contratação de pessoal de apoio para atendimento aos alunos com deficiência e vedam o repasse dos custos para os pais, também são destacadas. Da Lei Brasileira de Inclusão, Lei n. 13.146/2015 (BRASIL, 2015), são referidas previsões específicas para o âmbito educacional quanto aos direitos dos alunos com deficiência, além das competências da família, da escola e do Estado.

No conjunto, os documentos citados na recomendação justificam a necessidade de que as escolas contratem profissionais para o AEE, organizem salas de recursos multifuncionais e insiram a perspectiva inclusiva em seus regimentos. A Promotoria, ao promover encontros com professores e gestores das escolas privadas, coloca-se como parceira para a solução dos problemas, não apenas como um órgão que regula, fiscaliza, aciona e intervém. No contexto da inclusão, os direitos educacionais das pessoas com deficiência visam fazer com que o Estado possa "progressivamente retirar a grande rede de proteção coletiva que havia produzido. O chamado Estado-mínimo já não deve ser chamado a assistir à população, a providenciar serviços que protejam os indivíduos dos riscos" (SARAIVA, 2013). O Estado passa a ser agente e articulador da tarefa de "conduzir as condutas para a participação por meio da implementação e desenvolvimento de políticas que possibilitem acesso e acessibilidade para a permanência de cada sujeito no jogo econômico, político e social" (THOMA; KRAEMER, 2017, p. 70).

A recomendação à empresa Globo Comunicações e Participações S. A., por sua vez, estabelece medidas 
específicas para o desenvolvimento de ações antirracismo: a determinação da criação de um Grupo de Trabalho com a participação de atores negros e do movimento negro, a elaboração de um censo dos trabalhadores que prestam serviços à empresa, com recorte de raça/cor e gênero, e um levantamento sobre a representação das pessoas negras e o número de artistas negros(as) que aparecem em telenovelas, séries, propagandas, programas de entretenimento, entre outros produtos da empresa, bem como o de jornalistas e comentaristas (RIO DE JANEIRO, 2018). Desse modo, a produção desses dados aciona outras estratégias de governamento.

As lutas no campo do antirracismo no Brasil têm se consolidado, sobretudo, a partir das fortes demandas por reconhecimento das diferenças étnico-raciais sob um ponto de vista afirmativo. Nas palavras de Domingues, como resultado "da luta empreendida pelo movimento negro, há décadas assiste-se a uma mudança de postura, em vários segmentos da sociedade brasileira, em relação ao tratamento conferido às questões da população negra no país" (2005, p. 164).

Nesse contexto, foi institucionalizada uma série de espaços públicos estratégicos para a elaboração de políticas antirracismo, haja vista a criação do Estatuto da Igualdade Racial (BRASIL, 2010a), do Sistema Nacional de Promoção da Igualdade Racial (SNAPIR), regulamentado por meio do Decreto n. 8.136, em 2013, e da Secretaria Especial de Promoção da Igualdade Racial (SEPPIR), instituída pela Lei n. 10.678. Esse ambiente social criou condições para a inserção da temática nas políticas educacionais, destacando-se a Política de Cotas Raciais (BRASIL, 2012), que determina um percentual das vagas no Ensino Superior para indivíduos autodeclarados negros, e a legislação que institui a obrigatoriedade de ensino de História e Cultura Afro-brasileira e Africana na educação básica (BRASIL, 2003). Amparados por essa estrutura, os movimentos negros se fortaleceram na valorização da negritude e no combate ao racismo, requisitando espaços que colocavam a desigualdade racial em debate.

Considerando-se a mídia como um terreno potente no desenvolvimento de ações educacionais, os encaminhamentos de combate ao racismo e valorização da cultura afro-brasileira visam ocupar esses meios como forma de promover o protagonismo negro. Salientamos que o próprio Estatuto da Igualdade Racial prevê que as estratégias de combate à desigualdade racial possuem um caráter educativo, devendo ser alicerçadas em dimensões reparatórias e inclusivas, cuja repercussão deve abranger as múltiplas esferas sociais. Desse modo, o Ministério Público do Trabalho se ampara também nesse documento para recomendar a inserção imediata de maior número de artistas negros(as) na novela em questão. Considerando os produtos culturais como agentes de práticas inclusivas, o documento do MP argumenta que "as produções veiculadas pelos meios de comunicação devem valorizar a herança cultural e a participação da população negra na história do País"; além disso, "essas produções deverão adotar a prática de conferir oportunidades de emprego para atores figurantes e técnicos negros" (RIO DE JANEIRO, 2018, p. 5).

Salientamos os pontos da recomendação que determinam ações complementares ao atendimento de inserção de atrizes e atores negros nas produções da emissora, que objetivam promover a inserção da temática das diferenças étnico-raciais pela via da representatividade afirmativa:

- Realizar de imediato um censo dos trabalhadores que prestam serviços à empresa, empregados ou não, com recorte de raça/cor e gênero, possibilitando um observatório permanente [...] para ser utilizado como ferramenta para a tomada de decisões estratégicas de conscientização, qualificação, contratação e ascensão profissional;

- Promover internamente ações de conscientização sobre o racismo na sociedade e, externamente em mensagens publicitárias, programas jornalísticos e programação em geral (RIO DE JANEIRO, 2018, p. 8-9). 
Tais ações são elucidativas para a compreensão de que essas orientações delineiam práticas de produção de subjetividades inclusivas. Embora as documentações jurídicas sejam elaboradas com o tom impositivo da Lei, elas criam relevantes movimentos para a constituição das subjetividades a partir da produção das vontades. Ou seja, o estabelecimento de ações a serem cumpridas a partir de um conjunto de argumentos legais ${ }^{2}$, informações estatísticas e considerações relativas ao respeito pelos princípios democráticos de uma cidadania participativa, produz um espaço potente para a criação de estratégias que se estruturam pelo desejo de incluir, muito mais do que pelo cumprimento de demandas a partir de uma intervenção pura da Lei.

\section{Considerações Finais}

Para Hardt e Negri, os modos como uma sociedade traz suas leis e normas são "a cristalização de um conjunto de valores específicos, pois a ética faz parte da materialidade de qualquer fundamentação jurídica” (2001, p. 28). Esses valores estão colocados na legislação e sua efetivação tem como objetivo regular e conduzir a vida da população.

Ao longo do artigo, argumentamos que, embora a inclusão esteja inscrita numa busca por produzir condutas inclusivas e estabelecer outros modos de relação com as diferenças, as formas de discriminação e exclusão são parte de uma construção histórica que requer a intervenção do Estado. Entretanto, tal intervenção não se dá somente no sentido de obrigar a fazer, mas no de constituir subjetividades inclusivas, mediante o convencimento de que a inclusão deve acontecer. Dessa maneira, a lei surge também como uma forma de legitimação de verdades, atuando na promoção do desejo de incluir.

As recomendações são parte de um poder de Estado que regula ações e modos de ser e agir, e as estratégias de governamento para colocar a inclusão em funcionamento estão presentes nas leis, diretrizes e políticas que regulam e orientam o acesso e a participação dos sujeitos. Esses discursos estão na ordem dos saberes constituídos em uma governamentalidade biopolítica e democrática que busca conduzir as condutas no sentido da inclusão. Isso se dá mediante ações administrativas pautadas em diferentes documentos, mas, eventualmente, requerem também a via judiciária.

A operacionalização da lei mediante as normas presentes no conjunto de documentos legais que embasam as recomendações constitui mecanismo para colocar em funcionamento a razão de Estado. Todavia, a efetivação da inclusão implica o desenvolvimento de práticas que se inscrevem tanto no âmbito da gestão pública quanto no das relações entre os sujeitos. Nesse espaço relacional, fazem-se necessárias orientações legais que não se apresentem somente como normas a serem acatadas, mas estratégias que busquem desenvolver os desejos de incluir, constituindo subjetividades inclusivas. Entrar no jogo da inclusão passa a fazer parte de uma dinâmica que gravita em torno de verdades acerca da necessidade do desenvolvimento de ações inclusivas. Por intermédio do Poder Judiciário, o Estado regula os rumos da promoção da inclusão pela articulação entre fiscalização, intervenção e orientação, produzindo modos de ser inclusivos.

Nesse panorama, os contornos da inclusão podem ser pensados como sintomáticos de tempos ambíguos e paradoxais; tempos que reconhecem a necessidade da valorização das minorias e que mantêm, simultaneamente, lógicas excludentes em suas estruturas sociais. Nesse caminho, analisamos que é a necessidade da interferência do Poder Judiciário na promoção de ações de equidade e inclusão que permite a inscrição daquilo que aqui chamamos de judicialização da inclusão. 


\section{Notas}

1. Significados disponíveis em: http://michaelis.uol.com.br/moderno-portugues/busca/portugues-brasileiro/recomenda \%C3\%A7\%C3\%A3o/. Acesso em: 15 jun. 2018.

2. O documento da Notificação Recomendatória elenca 29 considerações argumentativas, nas quais 18 pontos referenciam alguma legislação vigente no país.

\section{Contribuição das Autoras}

Conceptualização: Thoma AD, Hillesheim B, Siqueira CFC; Redação - Primeira Versão: Thoma AD; Redação - Revisão \& Edição: Hillesheim B, Siqueira CFC.

\section{REFERÊNCIAS}

BRASIL. Constituição Federal de 1988. Brasília, DF: Presidência da República, 1988.

BRASIL. Lei n. 9.394, de 20 de dezembro de 1996. Lei de Diretrizes e Bases da Educação Nacional. Brasília, DF: Presidência da República, 1996.

BRASIL. Lei n. 10.639, de 09 de janeiro de 2003. Institui a obrigatoriedade do Ensino de História e Cultura Afro-brasileira e Africana na Educação Básica. Brasília, DF: Presidência da República, 2003.

BRASIL. Decreto n. 5.296, de 02 de dezembro de 2004. Fixa normas de acessibilidade nas escolas. Brasília, DF: Presidência da República, 2004.

BRASIL. Decreto n. 6.949, de 25 de agosto de 2009. Promulga a Convenção Internacional sobre os Direitos das Pessoas com Deficiência. Brasília, DF: Presidência da República, 2009a.

BRASIL. Conselho Nacional de Educação. Resolução CNE/ CEB n. 04, de 02 de outubro de 2009. Institui que o Atendimento Educacional Especializado deve estar previsto no Projeto Pedagógico das escolas. Brasília, DF: Presidência da República, 2009b.

BRASIL. Lei n. 12.288, de 20 de julho de 2010. Estatuto da Igualdade Racial. Brasília, DF: Presidência da República, 2010a.

BRASIL. Ministério da Educação. Secretaria de Educação Especial. Nota técnica CGPEE/GAB n. 15, de 02 de julho de 2010. Regulamenta a contratação de pessoal de apoio ao atendimento de alunos com deficiência. Brasília, DF: Presidência da República, 2010b.

BRASIL. Ministério da Educação, Secretaria de Educação Especial. Nota técnica SEESP/GAB n. 19, de 08 de setembro de 2010. Veta o repasse de custos com o Atendimento Educacional Especializado aos pais dos alunos com deficiência. Brasília, DF: Presidência da República, 2010c.

BRASIL. Decreto n. 7.611, de 17 de novembro de 2011. Normatiza o Atendimento Educacional Especializado nas escolas. Brasília, DF: Presidência da República, 2011. 
BRASIL. Lei n. 12.711, de 29 de agosto de 2012. Lei de cotas para o Ensino Superior. Brasília, DF: Presidência da República, 2012.

BRASIL. Decreto n. 8.136, de 05 de novembro de 2013. Regulamenta o Sistema Nacional de Promoção da Igualdade Racial (SNAPIR). Brasília, DF: Presidência da República, 2013.

BRASIL. Lei n. 13.146, de 06 de julho de 2015. Lei Brasileira de Inclusão. Brasília, DF: Presidência da República, 2015.

CASTEL, R. As armadilhas da exclusão. In: CASTEL, R.; WANDERLEY, L. E.; BELFIORE-WANDELEY, M. (orgs.). Desigualdade e a questão social. São Paulo: EDUC, 2007. p. 17-50.

CHRISPINO, Á.; CHRISPINO, R. S. P. A judicialização das relações escolares e a responsabilidade civil dos educadores. Ensaio: avaliação de políticas públicas educacionais, Rio de Janeiro, v. 16, n. 58, p. 9-30, jan./ mar. 2008. https:// doi.org/10.1590/S0104-40362008000100002

DOMINGUES, P. Espaço Aberto - ações afirmativas para negros no Brasil: o início de uma reparação histórica. Revista Brasileira de Educação, Rio de Janeiro, n. 29, p. 164-176, 2005. https:// doi.org/10.1590/ S1413-24782005000200013

FOUCAULT, M. Em defesa da sociedade. São Paulo: Martins Fontes, 2005.

FOUCAULT, M. Segurança, território e população. São Paulo: Martins Fontes, 2008.

FOUCAULT, M. O governo de si e dos outros. São Paulo: Martins Fontes, 2013.

GALLO, S. O pequeno cidadão: sobre a condução da infância em uma governamentalidade democrática. In: RESENDE, A. (org.). Michel Foucault: o governo da infância. Belo Horizonte: Autêntica, 2015. p. 329-343.

HARDT, M.; NEGRI, A. Império. Rio de Janeiro: Record, 2001.

HILLESHEIM, B.; BERNARDES, A. Políticas de inclusão: a arte de governar a partir da liberdade. Psicologia em Estudo, Maringá, v. 20, n. 1, p.129-137, jan./mar. 2015. https://doi.org/10.4025/psicolestud.v20i1.25675

IBGE. Mapa de Distribuição Espacial. Rio de Janeiro: Ministério do Planejamento, Orçamento e Gestão, 2013.

LEMOS, F. C. S. A judicialização da vida no campo das relações entre a norma e a lei: mecanismos de poder e resistências na assistência social e na saúde. In: BRIZOLA, A. L. C.; ZANELLA, A. V.; GESSER, M. (orgs.). Práticas Sociais, Políticas Públicas e Direitos Humanos. Florianópolis: ABRAPSO-NUPPE/CFH/UFSC, 2013. p. 127-140.

MEYER, D. E.; PARAÍSO, M. A. Metodologias de pesquisa pós-críticas ou sobre como fazemos nossas investigações. In: MEYER, D. E.; PARAÍSO, M. A. (orgs.). Metodologias de pesquisas pós-críticas em educação. Belo Horizonte: Mazza Edições, 2012. p. 15-22.

MENEZES, E. C. P. A maquinaria escolar na produção de subjetividades para uma sociedade inclusiva. 2011, 189 f. Tese (Doutorado em Educação) - Programa de Pós-graduação em Educação, Universidade do Vale do Rio dos Sinos, São Leopoldo, 2011. 
NOGUEIRA, C. La gubernamentalidad en los cursos del profesor Foucault. Educação \& Realidade, Porto Alegre, v. 20, n. 2, p. 21-32, mar./ago. 2009.

OLIVEIRA, C. F. B.; BRITO, L. M. T. Judicialização da vida na contemporaneidade. Psicologia Ciência e Profissão, Brasília, v. 33, n. SPE, p. 78-89, 2013.

POL-DROIT, R. Michel Foucault, Entrevistas. Rio de Janeiro: Graal, 2006.

REIS, C.; GUARESCHI, N. M. F.; CARVALHO, S. Sobre jovens drogaditos: as histórias de ninguém. Psicologia \& Sociedade, Recife, v. 26, p. 68-78, 2014. https:// doi.org/10.1590/S0102-71822014000500008

RIO DE JANEIRO, Ministério Público do Trabalho. Notificação Recomendatória n. 163.181. Rio de Janeiro: Procuradoria Regional do Trabalho da 1ª Região, 2018.

RIO GRANDE DO SUL. Parecer n. 1400/2002. Fixa normas para os alunos com deficiência no Ensino Fundamental. Porto Alegre: Conselho Estadual de Educação, 2002.

RIO GRANDE DO SUL. Parecer n. 56/2006. Estabelece normas para a inclusão dos alunos com deficiência. Porto Alegre: Conselho Estadual de Educação, 2006.

RIO GRANDE DO SUL, Parecer n. 211/2010. Estabelece normas para a certificação dos alunos com deficiência. Porto Alegre: Conselho Estadual de Educação, 2010.

RIO GRANDE DO SUL. Ministério Público. Notificação Recomendatória n. 03/2017. Porto Alegre: Promotoria de Justiça Regional de Educação, 2017.

SARAIVA, K. Educando para viver sem riscos. Educação, Porto Alegre, v. 36, n. 2, p. 168-179, maio/ago. 2013.

THOMA, A. S.; KRAEMER, G. M.. A educação de pessoas com deficiência no Brasil: políticas e práticas de governamento. Curitiba: Appris, 2017.

TIBÉRIO, W. A judicialização das relações escolares: um estudo sobre a produção de professores. 2011. 155 f. Dissertação (Mestrado em Educação) - Programa de Pós-graduação em Educação, São Paulo, Universidade de São Paulo, 2011.

VEIGA-NETO, A. Coisas de governo... In: RAGO, M.; ORLANDI, L. L.; VEIGA-NETO, A. (orgs.). Imagens de Foucault e Deleuze: ressonâncias nietzschianas. 2. ed. Rio de Janeiro: DP\&A. p. 13-34, 2005.

Recebido: 01 Out. 2019

Aceito: 10 Set. 2020

Editoras Associadas:

Daniela Dias dos Anjos e Ana Luiza Bustamante Smolka 